\title{
PENGARUH SERVICE EXPERIENCE DAN PERCEIVED VALUE TERHADAP KEPUASAN PASIEN PADA INSTALAS RAWAT INAP DI RSUD KOTA MAKASSAR
}

\section{INFLUENCE OF SERVICE EXPERIENCE AND PERCEIVED VALUE ON PATIENT SATISFACTION AT INPATIENT INSTALLATION AT RSUD KOTA MAKASSAR}

\author{
Ika Fadhilah Bea ${ }^{l}$, Syahrir A. Pasinringi ${ }^{l}$, Andi Zulkifli ${ }^{2}$ \\ ${ }^{1}$ Bagian Manajemen Rumah Sakit, Fakultas Kesehatan Masyarakat, Universitas Hasanuddin, \\ ${ }^{2}$ Bagian Epidemiologi, Fakultas Kesehatan Masyarakat, Universitas Hasanuddin, Makassar
}

Alamat Korespondensi: Ika Fadhilah Bea, Fakultas Kesehatan Masyarakat, Universitas Hasanuddin Makassar, 90245, HP: 085243564492,Email: IkaFadhilahBea@yahoo.co.id

\begin{abstract}
Abstrak
Pengalaman layanan (service experience) dan nilai yang dirasakan (perceived value) yang terjadi pada setiap interaksi antar pasien dan pemberi layanan akan mempengaruhi kepuasan pasien (patient satisfaction). Penelitian ini bertujuan untuk menganalisis pengaruh service experience dan perceived value terhadap kepuasan pasien pada Instalasi Rawat Inap di RSUD Kota Makassar. Penelitian ini dilaksanakan pada Instalasi Rawat Inap RSUD Kota Makassar. Metode yang digunakan dalam penelitian ini adalah cross sectional dengan menyebarkan kuesioner pada 180 pasien sebagai responden. Pengambilan sampel dilakukan dengan menggunakan teknik proportional stratified random sampling dari setiap kelas perawatan di lokasi penelitian. Data dianalisis dengan menggunakan uji regresi linear sederhana untuk melihat pengaruh masing-masing variabel service experience dan perceived value terhadap kepuasan pasien yang dilanjutkan dengan uji regresi linear berganda untuk melihat pengaruh secara simultan variabel independen terhadap variabel dependen. Hasil penelitian menunjukkan bahwa terdapat pengaruh service experience terhadap kepuasan pasien dengan besar pengaruhnya $R^{2} 26.7 \%$ yang ditunjukkan dengan $\mathrm{t}$ hitung $=8.046>\mathrm{t}$ table $=1.960$ dengan nilai $\mathrm{p}=0.001<0.05$. Terdapat pengaruh perceived value terhadap kepuasan pasien dengan besar pengaruhnya $R^{2} 21.2 \%$ yang ditunjukkan dengan $\mathrm{t}$ hitung $=6.926>\mathrm{t}$ table $=1.960$ dengan nilai $\mathrm{p}=0.001<0.05$. Terdapat pengaruh secara simultan service experience dan perceived value terhadap kepuasan pasien dengan besar pengaruhnya adjusted $R^{2} 26.4 \%$ ditunjukkan dengan $\mathrm{F}$ hitung $=33.161>\mathrm{F}$ table $=19.50$ dengan nilai $\mathrm{p}=0.001<0.05$. Disimpulkan bahwa service experience dan perceived value serta secara simultan mempengaruhi kepuasan pasien. Diharapkan perhatian yang besar dalam memberikan service experience terbaik serta meningkatkan perceived value terhadap pelayanan di rumah sakit. Kata Kunci : Service experience, perceived value, kepuasan pasien.
\end{abstract}

\begin{abstract}
Service experience and perceived value in every interaction between patient and services provider will influence customer satisfaction. This study aimed to analyze the influence of service experience and perceived value to the satisfaction of the patients in the inpatient ward at the Hospital of Makassar. The research was conducted at the Inpatient Hospital Makassar. The method used in this study is a cross sectional study by distributing questionnaires to 180 as respondents. Sampling was done by using stratified random sampling of each class of treatment in the study site. Data were analyzed using simple linear regression test to see the effect of each variable service experience and perceived value to the satisfaction of patients, followed by multiple linear regression tests for the simultaneous viewing of independent variable on the dependent variable. The results showed that there were significant service experience against big influence patient satisfaction with $R^{2} 26.7 \%$ as indicated by $t$ score $=8.046>t$ table $=1.960$ with $p=0.001<0.05$. There was the influence of perceived value against major influence patient satisfaction with $R^{2} 21.2 \%$ as indicated by $t$ score $=6.926>t$ table $=1.960$ with $p=0.001<0.05$. There was influence of simultaneous service experience and perceived value against major influence patient satisfaction with adjusted $R^{2} 26.4 \%$ indicated by $F$ score $=33.161>F$ table $=19.50$ with a value of $p=0.001<0.05$. It was concluded that service experience and perceived value and simultaneously affect patient satisfaction. It is expected that great attention in providing the best service experience and increase perceived value of hospital services.
\end{abstract}

Keywords: Service experience, perceived value, patient satisfaction. 


\section{PENDAHULUAN}

Kepuasan pasien dalam pelayanan kesehatan merupakan komponen penting dari kinerja organisasi di lingkungan rumah sakit (Koné Péfoyo and Wodchis, 2013). Kepuasan pasien mengacu pada sejauh mana harapan, sasaran, dan preferensi yang diinginkan oleh pasien dipenuhi oleh penyedia layanan kesehatan (Huei, Mee and Chiek, 2015). Kepuasan pasien yang lebih besar terhadap perawatan akan menjadikan pasien patuh terhadap perintah dokter, lebih loyal, kesan positif dari mulut ke mulut oleh pasien, mengurangi jumlah keluhan pasien, keuntungan yang lebih tinggi, tingkat pengembalian pasien yang lebih tinggi dan rujukan pasien yang lebih banyak (Zarei et al., 2015). Penelitian yang ada menunjukkan bahwa pasien yang puas cenderung mengikuti petunjuk pengobatan dan saran medis, mungkin karena mereka lebih cenderung percaya bahwa pengobatan akan efektif (Arab et al., 2014). Kemampuan setiap organisasi untuk memuaskan pelanggannya paling mudah direalisasikan bila harapan tersebut dikelola agar sesuai dengan produk dan proses yang ada (Alrubaiee, 2011).

Berdasarkan beberapa hasil penelitian sebelumnya menunjukkan bahwa kepuasan pasien sangat dipengaruhi oleh service experience (Guo, 2012; Khan et al., 2015; Maklan et al., 2011; Dobrota et al., 2012; Yulianti, 2017). Tseng et al., (1999) menyatakan bahwa service experience dapat memiliki dampak signifikan pada kepuasan pelanggan. Sedangkan Haeckel et al. (2003) dan Leonard et al. (2006) menyatakan bahwa petunjuk (service clues) mempengaruhi kepuasan melalui persepsi yang terbentuk pada setiap pengalaman layanan.

Selain itu, perceived value juga mempengaruhi kepuasan pasien. Berdasarkan hasil penelitian sebelumnya menujukkan bahwa kepuasan sangat dipengaruhi oleh perceived value (Wu et al., 2016; Nazri et al., 2016). Perceived value adalah salah satu elemen terpenting untuk mendapatkan keunggulan kompetitif dan dianggap sebagai prediktor yang signifikan terhadap kepuasan (Cronin et al.,2000; McDougall et al., 2000). Hal ini didukung dengan berbagai penulis seperti Hanan dan Karp serta Iglesias dan Guillen yang dikutip oleh Ali (2007) mengemukakan bahwa ada korelasi unik antara nilai yang dirasakan dan kepuasan pelanggan.
Perceived value berperan penting dalam meningkatkan tingkat kepuasan pasien (Moliner, 2009). Hal ini mengindikasikan bahwa kepuasan pasien akan lebih tinggi bila perceived value dan kualitasnya melebihi harapan pasien (Surydana, 2017). Nilai yang dirasakan pelanggan dapat digambarkan sebagai evaluasi untuk membandingkan persepsi tentang nilai yang dirasakan dan hasil nyata dari pengalaman pembelian (Chiang et al., 2013). Sedangkan Leonard et al. (2006) menyatakan bahwa kepuasan berasal dari persepsi yang terbentuk pada setiap pengalaman layanan ketika terjadi interaksi antara pelanggan dan pemberi layanan. Dengan interaksi, pelanggan menilai nilainya tidak dalam tahap pembelian namun selama tahap konsumsi atau penggunaan layanan (Akbar et al., 2016). Pengalaman ini dipengaruhi oleh petunjuk sensorik dan emosional yang membangkitkan suatu persepsi baik yang bersifat rasional maupun emosional, dan berpengaruh terhadap kepuasan (Leonard et al., 2006; Prabhu et al., 2016).

Rumah sakit sebagai institusi pelayanan publik diwajibkan untuk memenuhi kepuasan pasien. RSUD Kota Makassar merupakan Pusat Rujukan Pintu Gerbang Utara Makassar Kelas $\mathrm{B}$ telah melakukan survey kepuasan pasien di Instalasi Rawat Inap pada Tahun 2015, 2016 dan 2017 dengan capaian tingkat kepuasan pasien rata-rata adalah sebesar $79.67 \%$. Hal ini menunjukkan tingkat kepuasan pasien yang belum memenuhi standar yaitu sebesar $\geq 90 \%$ berdasarakan Kepmenkes No.129 Tahun 2008 tentang Standar Pelayanan Minimal Rumah Sakit. Dengan demikian, berdasarkan masalah tersebut penelitian ini dilakukan untuk melihat pengaruh service experience dan perceived value terhadap kepuasan pasien pada Instalasi Rawat Inap di RSUD Kota Makassar.

\section{BAHAN DAN METODE Lokasi dan Rancangan penelitian}

Penelitian ini dilakukan di Instalasi Rawat Inap RSUD Kota Makassar. Jenis penelitian yang digunakan adalah observasional analtik dengan rancangan cross sectional study.

\section{Populasi dan sampel}

Populasi adalah seluruh pasien yang sedang menjalani perawatan di Instalasi Rawat Inap RSUD Kota Makassar. Sampel sebanyak 180 pasien yang dipilih secara proportional stratified random sampling yang telah memenuhi kriteria inklusi yaitu tidak menderita penyakit jiwa dan gangguan panca indera, 
pasien dalam keadaan sadar dan dapat diajak bekomunikasi, dan pasien yang telah dirawat sekurang-kurangnya 3 (tiga) hari.

\section{Metode pengumpulan data}

Pengumpulan data dilakukan oleh peneliti dengan menggunakan kuesioner. Kuesioner yang digunakan adalah kuesioner service experience, perceived value dan kepuasan pasien. Adapun kuesioner service experience diadaptasi dari kuesioner yang dibuat oleh Yulianti (2017), yang terdiri dari 30 item pernyataan. Sementara kuesioner perceived value diadaptasi dari Moliner (2006) dan diterjemahkan ke dalam Bahasa Indonesia yang terdiri dari 25 item pernyataan. Begitupun dengan kuesioner Kepuasan Pasien menggunakan kuesioner PSQ18 oleh Marshall et al., (1994) dan diterjemahkan ke dalam Bahasa Indonesin yang terdiri dari 9 item penryataan positif dan 9 pernyataan negatif.

\section{Analisis data}

Analisis data yang digunakan untuk melihat pengaruh masing-masing variabel service experience dan perceived value terhadap kepuasan pasien adalah menggunakan uji regresi linear sederhana. Sedangkan analisis data yang digunakan untuk melihat pengaruh secara simultan service experience dan perceived value terhadap kepuasan pasien adalah meggunakan uji regresi liner berganda.

\section{HASIL}

\section{Karakteristik sampel}

Tabel 1 memperlihatkan distribusi frekuensi karateristik responden di lokasi penelitian yang menunjukkan bahwa sebagian besar responden yakni $31.7 \%$ berada dalam kelompok umur 25-34 Tahun. dilihat dari jenis kelamin, jumlah laki-laki dan perempuan sangat jauh berbeda yaitu laki-laki sebesar 25\% sedangkan perempuan sebesar $75 \%$. Berdasarkan jenis pekerjaan terbanyak yaitu sebagai ibu rumah tangga $46.7 \%$ dengan penghasilan responden sebagian besar yaitu $\mathrm{Rp}$ 1.000 .000 - Rp 2.500.000 sebesar $43.9 \%$. Serta berdasarkan jenis pembiyaan sebagian besar adalah BPJS yaitu sebesar $56.1 \%$ dengan tingkat pendidikan responden terbanyak yaitu SMA/SMK /SLTA sebasar $44.4 \%$.

Selain itu, distribusi frekuensi responden berdasarkan kelas perawatan secara proporsif dengan jumlah responden yang terbesar yaitu berasal dari kelas perawatan pada kelas 3 yakni $56.7 \%$. Serta berdasarkan jenis pelayanan medik spesialis dasar sebaran responden secara proporsif yang tebesar berasal dari penyakit dalam/interna yakni $38.9 \%$ dan sebagian besar responden tidak pernah dirawat di rumah sakit ini sebelumnya yaitu sebesar $64.4 \%$ serta sebagaian responden yang tidak pernah dirawat di rumah sakit lain sebelumnya yaitu sebesar $63.9 \%$.

\section{Analisis Univariat}

Hampir semua responden yakni $97.8 \%$ berada dalam kategori service experience yang tergolong baik, sehingga dapat disimpulkan bahwa service experience tergolong baik di Instalasi Rawat Inap RSUD Kota Makassar. Selain itu, data tampak terlihat bahwa hampir semua responden yakni $92.8 \%$ berada dalam kategori perceived value yang tergolong baik, sehingga dapat disimpulkan bahwa perceived value tergolong baik di Instalasi Rawat Inap RSUD Kota Makassar. Berdasarkan Kepuasan pasien menunjukkan bahwa hampir semua responden yakni $90.0 \%$ berada dalam kategori kepuasan pasien yang tergolong puas, sehingga dapat disimpulkan bahwa kepuasan pasien tergolong puas di Instalasi Rawat Inap RSUD Kota Makassar.

\section{Analisis Bivariat}

Kotak Model Summary didapatkan nilai $R$ Square sebesar 0.267 artinya pengaruh variable service experience terhadap kepuasan pasien adalah sebesar $26.7 \%$ sedangkan sisanya disebabkan oleh variable lain. Dari kotak coefficients didapatkan nilai koefisien regresi (B) sebesar 0.256 bernilai positif maka dengan demikian dikatakan bahwa service experience berpengaruh positif terhadap terhadap kepusan pasien, jika service experience meningkat maka kepuasan pasien juga meningkat. Selain itu, berdasarkan ouput pada table coefficients diatas didapatkan nilai signifikansi (Sig.) sebesar 0.001 lebih kecil dari 0.05 , sehingga dapat bahwa ada pengaruh service experience terhadap kepuasan pasien di Instalasi Rawat Inap RSUD Kota Makassar.

Tabel 1 memperlihatkan bahwa dari kotak Model Summary didapatkan nilai $R$ Square sebesar 0.212 artinya pengaruh variable perceived value terhadap kepuasan pasien adalah sebesar $21.2 \%$ sedangkan sisanya disebabkan oleh variable lain. Dari kotak coefficients didapatkan nilai koefisien regresi (B) sebesar 0.259 bernilai positif maka dengan demikian dikatakan bahwa perceived value berpengaruh positif terhadap terhadap kepusan pasien, jika perceived value meningkat maka kepuasan pasien juga meningkat. Selain itu, berdasarkan ouput pada table coefficients diatas didapatkan nilai signifikansi (Sig.) sebesar 
Table 1. Pengaruh Perceived Value terhadap Kepuasan Pasien pada Instalasi Rawat Inap RSUD Kota Makassar Tahun 2017

ANOVA $^{\mathrm{a}}$

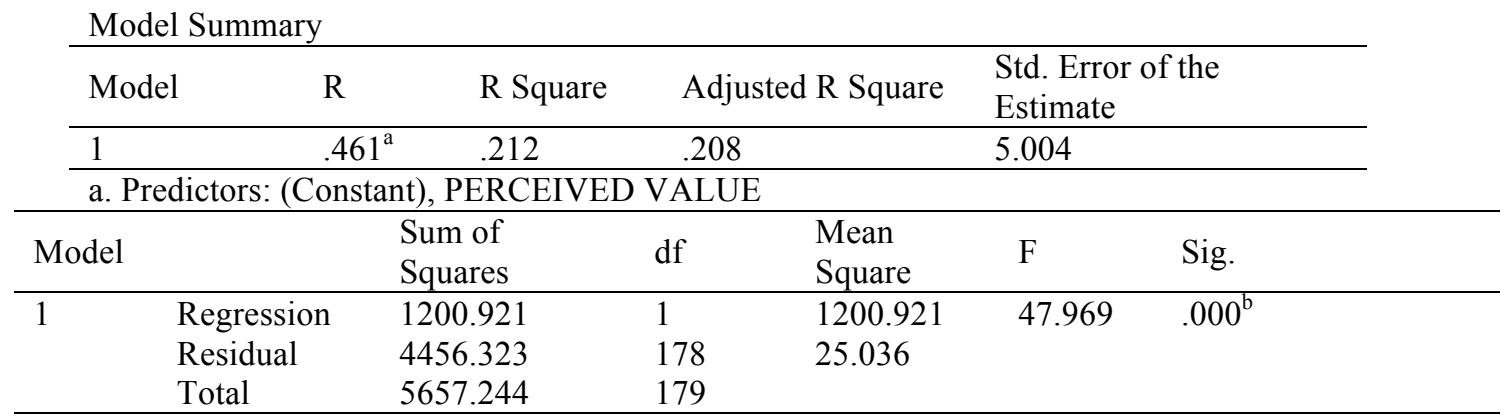

a. Dependent Variable: KEPUASAN PASIEN

Coefficients

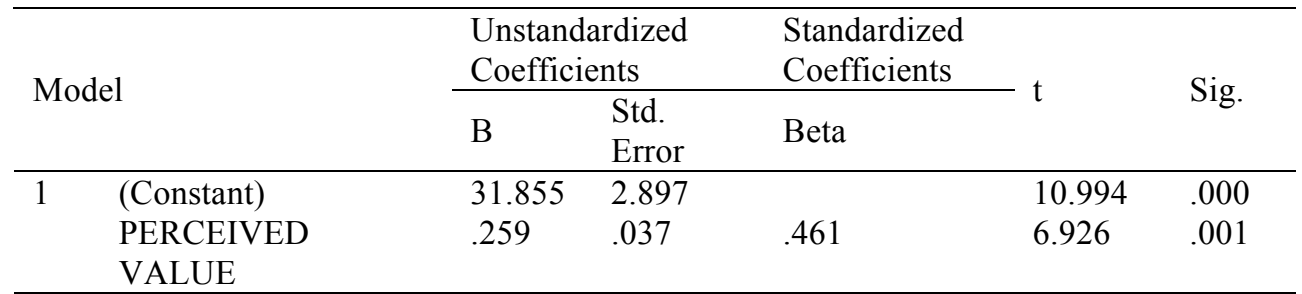

a. Dependent Variable: KEPUASAN PASIEN

b. Predictors: (Constant), PERCEIVED VALUE

Table 2. Pengaruh Service Experience dan Perceived Value secara Simultan terhadap Kepuasan Pasien pada Instalasi Rawat Inap RSUD Kota Makassar Tahun 2017

\begin{tabular}{|c|c|c|c|c|}
\hline Model & $\mathrm{R}$ & R Square & $\begin{array}{l}\text { Adjusted R } \\
\text { Square }\end{array}$ & Std. Error of the Estimate \\
\hline 1 & $.522^{\mathrm{a}}$ & .273 & .264 & 4.822 \\
\hline
\end{tabular}

\begin{tabular}{|c|c|c|c|c|c|}
\hline \multicolumn{6}{|l|}{ ANOVA $^{\mathrm{a}}$} \\
\hline Model & Sum of Squares & $\mathrm{df}$ & Mean Square & $\mathrm{F}$ & Sig. \\
\hline \multirow{3}{*}{$\begin{array}{ll}1 & \text { Regression } \\
& \text { Residual } \\
& \text { Total }\end{array}$} & 970.957 & 2 & 770.987 & 33.161 & $.001^{\mathrm{b}}$ \\
\hline & 3646.620 & 177 & 23.250 & & \\
\hline & 4617.578 & 179 & & & \\
\hline
\end{tabular}

a. Dependent Variable: KEPUASAN PASIEN

b. Predictors: (Constant), PERCEIVED VALUE, SERVICE EXPERIENCE

Coefficients $^{\mathrm{a}}$

\begin{tabular}{|c|c|c|c|c|c|}
\hline \multirow{2}{*}{ Model } & \multicolumn{2}{|c|}{$\begin{array}{l}\text { Unstandardized } \\
\text { Coefficients }\end{array}$} & \multirow{2}{*}{$\begin{array}{l}\text { Standardized } \\
\text { Coefficients } \\
\text { Beta }\end{array}$} & \multirow{2}{*}{$\mathrm{t}$} & \multirow{2}{*}{ Sig. } \\
\hline & B & $\begin{array}{l}\text { Std. } \\
\text { Error }\end{array}$ & & & \\
\hline $1 \quad$ (Constant) & 26.671 & $\begin{array}{l}3.10 \\
3\end{array}$ & & 8.595 & .000 \\
\hline SERVICE EXPERIENCE & .204 & .053 & .413 & 3.830 & .001 \\
\hline PERCEIVED VALUE & .072 & .061 & .129 & 1.195 & .234 \\
\hline
\end{tabular}


0.001 lebih kecil dari 0.05 , sehingga dapat disimpulkan bahwa ada pengaruh perceived value terhadap kepuasan pasien di Instalasi Rawat Inap RSUD Kota Makassar.

\section{Analisis Mulitivariate}

Table 2 memperlihatkan bahwa dari kotak Model Summary didapatkan nilai Adjusted $R$ Square sebesar 0.264 artinya sumbangan atau pengaruh variabel service experience dan perceived value terhadap kepuasan pasien adalah sebesar 26.4\% sedangkan sisanya disebabkan oleh variable lain. Kemudian pada kotak Anova tampak bahwa hasil uji $\mathrm{F}$ yang menunjukkan nilai $\mathrm{p}$ (Sig.) sebesar 0.001 lebih kecil dari 0.05 , sehingga dapat disimpulkan bahwa variable servce experience dan perceived value mempuanyai pengaruh simultan yang signifikan terhadap kepuasan pasien di Instalasi Rawat Inap RSUD Kota Makassar.

Dari kotak coefficients didapatkan nilai Unstandardized Coefficients $(\mathrm{Bo})=26.671$, nilai $\mathrm{B} 1=0.204$ dan $\mathrm{B} 2=0.072$. Namun hanya variabel service experience yang mempunyai nilai p (Sig.) sebesar 0.001 lebih kecil dari 0.05 , sehingga dapat disimpulkan bahwa hanya variabel service experience mempunyai pengaruh terhadap kepuasan pasien sedangkan variabel perceived value hanya sebagai konfonding faktor. Hal ini berarti bahwa setiap peningkatan sebesar 1 satuan service experience maka akan meningkatkan kepuasan pasien sebesar 0.204 satuan setelah dikontrol variabel perceived value.

Selanjutnya, pada kolom Beta dapat digunakan untuk mengetahui variabel mana yang paling besar pengaruhnya dalam menentukan variabel dependennya (kepuasan pasien). Semaikn besar nilai Beta semakin besar pengaruhnya terhadap variabel dependennya. Dari hasil nilai Coeffisien Beta didaptkan bahwa variabel service experience mempuanyai nilai paling besar dengan demikian dapat disimpulkan bahwa variabel service experience yang paling besar pengaruhnya (dominan) terhadap kepuasan pasien.

\section{PEMBAHASAN}

Penelitian ini menemukan bahwa secara signifikan service experience mempengaruhi kepuasan pasien di Instalasi Rawat Inap RSUD Kota Makassar. Hal ini menunjukkan bahwa tingkat kepuasan pasien dipengaruhi oleh pengalaman total yang dirasakan saat mendapatkan layanan. Jika pasien merasakan pengalaman yang kurang baik secara keseluruhan maka pasien menjadi kurang puas begitupun sebaliknya jika pasien merasakan pengalaman yang baik secara keseluruhan maka pasien menjadi puas.

Hasil penelitian ini sejalan dengan penelitian yang dilakukan oleh Yulianti (2017) kepada 293 responden yang menemukan bahwa terdapat pengaruh yang signifikan antara service experience dengan kepuasan pelanggan di Instalasi Rawat Inap RSUD AM Parikesit. Jika pelanggan merasakan pengalaman yang baik secara keseluruhan ketika menerima suatu layanan maka pelanggan akan puas. Selain itu terdapat beberapa panelitian yang juga menunjukkan bahwa kepuasan pelanggan sangat dipengaruhi oleh service experience (Guo, 2012; Khan et al., 2015; Maklan et al., 2011; Dobrota et al., 2012). Tseng et al. (1999) menyatakan bahwa service experience dapat memiliki dampak signifikan pada kepuasan pelanggan. Demikian halnya Haeckel et al. (2003) dan Leonard et al. (2006) menyatakan bahwa setiap pengalaman yang terjadi pada interaksi antara pelanggan dengan pemberi layanan akan berpengaruh terhadap kepuasan.

Ditribusi responden berdasarkan variable sevice exoerience dapat dilihat bahwa responden pada Instalaasi Rawat Inap RSUD Kota Makassar memeiliki service experience yang tergolong baik dengan persentasi sebasar $97.8 \%$. Berdasarkan ketiga indikator dari service experience, dapat diketahui bahwa indikator yang paling baik pada indikator functional clues dan indikator humanic clues sebesar $97.8 \%$. Kemudian indikator mechanic clues sebesar $91.7 \%$. Penelitian yang dilakukan oleh Yulianti (2017) menemukan bahwa terdapat pengaruh yang signifikan functional clues, humanic clues dan mechanic clues terhadap kepuasan pasien dengan functional clue memliki pengaruh yang paling besar.

Functional clues merupakan hal yang penting dalam pelayanan kesehatan sebab orang yang pergi ke rumah sakit untuk penyakit mereka dan mereka ingin disembuhkan dari penyakitnya terlebih dahulu. Sebagian besar responden mengutarakan kesan positif terhadap pelayanan yang disediakan oleh rumah sakit di antaranya dokter yang merawatnya mengetahui dengan baik tentang kondisi penyakit serta pengobatan yang diperlukan. Selain itu, dokter rutin memeriksa keadaan pasien dan dokter yang melayani bisa mendiagnosa dengan cepat setelah mendapat uji dalam beberapa tes kesehatan sebagaiamana yang diutarakan pasien dalam pertanyaan terbuka penelitian. 
Leonard et al. (2006) mengemukakan bahwa humanic clues sangat penting dalam melebihi harapan pelanggan terhadap layanan interaktif intensif karyawan, karena perawatan pelanggan sangat penting bagi pengalaman layanan. Selain itu mechanic clues juga berperan penting dalam membuat kesan pertama yang positif pada pelanggan. Karena dalam konsumsi layanan, pelanggan membeli layanan sebelum benar-benar mengalaminya. Petunjuk mekanis sangat penting untuk layanan di mana pelanggan merasakan fasilitas untuk jangka waktu yang lama, seperti rumah sakit (Berry et al., 2006).

Penelitian ini juga menemukan bahwa secara signifikan perceived value mempengaruhi kepuasan pasien di Instalasi Rawat Inap RSUD Kota Makassar. Hal ini menunjukkan bahwa tingkat kepuasan pasien dipengaruhi oleh nilai yang dirasakan. Jika pasien merasakan nilai yang kurang baik maka pasien menjadi kurang puas begitupun sebaliknya jika pasien merasakan nilai yang baik maka pasien menjadi puas di Instalasi.

Hasil penelitian ini sejalan dengan penelitian yang dilakukan oleh $\mathrm{H}$. Wu et al. (2016) kepada 452 responden medical tourist dari Cina yang menemukan bahwa perceived value berpengaruh positif terhadap kepuasan pasien. Selain itu, terdapat beberapa penelitian yang juga menunjukkan bahwa kepuasan sangat dipengaruhi oleh perceived value (Nazri et al., 2016; Li, 2013; Cronin Jr et al., 2000). Milfelner (2009) dalam penelitiannya menemukan bahwa perceived value sangat mempengaruhi kepuasan pelanggan. Selain itu, Rahmani et al. (2017) dalam peneltiannya juga menunjukkan bahwa terdapat hubungan yang signifikan antara perceived value dan kepuasan pasien. Demikian halnya Surydana (2017) mengemukakan bahwa perceived value berpengaruh signifikan terhadap kepuasan pasien dan kepuasan pasien dapat membangun hubungan jangka panjang. Hal ini mengindikasikan bahwa kepuasan akan lebih tinggi bila perceived value melebihi harapan pasien (Surydana, 2017).

Ditribusi responden berdasarkan variabel perceived value dapat dilihat bahwa responden pada Instalasi Rawat Inap RSUD Kota Makassar memeiliki perceived value yang tergolong baik dengan persentasi sebasar $92.8 \%$. Berdasarkan ketujuh indikator dari perceived value, dapat diketahui bahwa indicator yang paling baik pada indikator installation sebesar 98.9\%. Kemudian indikator professionalism sebesar 95\%, social sebesar $94.4 \%$, monetory cost sebesar $93.9 \%$, non monetory cost sebesar $92.8 \%$, perceived quality sebesar $88.9 \%$ dan indikator emotional sebesar $87.8 \%$. Adapun indikator yang paling rendah adalah emotional, hal ini dikarenakan pasien kurang merasa senang dengan suasana rumah sakit terkait dengan fasilitas ruang perawatan diantaranya ketersediaan air yang kadang terbatas, listrik yang sering padam, AC yang tidak berfungsi dengan baik dan biaya parkiran yang begitu mahal. Penelitian Moliner (2006) yang menunjukkan bahwa persepsi kualitas dan emosional merupakan penentu yang penting dari perceived value. Emosional dapat mempengaruhi kepuasan pasien (Moliner, 2006).

Penelitian ini juga menemukan bahwa secara simultan terdapat pengaruh service experience dan perceived value terhadap kepuasan pasien dengan service experience yang paling besar pengaruhnya (dominan) terhadap kepuasan pasien pada Instalasi Rawat Inap di RSUD Kota Makassar. Hal ini berarti pasien lebih menekankan pada service experience meskipun peran perceived value juga menentukan kepuasan pasien. Ini disebabkan karena karakteristik pasien cenderung sama yang didominasi oleh pasien dengan jenis pembayaran menggunakan pihak ketiga. Hal ini menghitung kurang pengorbanan yang diberikan sehingga pasien lebih menekan pada proses pelayanan yang didapatkan. Jika pelanggan merasakan pengalaman yang baik secara keseluruhan ketika menerima suatu layanan maka pelanggan akan puas (Yulianti, 2017). Konsep service experience telah digambarkan sebagai inti dari penawaran layanan dan desain layanan (Helkkula, 2011).

Hasil penelitian ini sejalan degan $\mathrm{H}$. $\mathrm{Wu}$ et al. (2016) dalam penelitiannya menemukan bahwa quality experience menjadi pendorong utama kepuasan pasien dibandingkan perceived value. Moliner (2006) juga mengemukakan bahwa kepuasan tergantung dari pengalaman menggunakan produk atau jasa.

\section{KESIMPULAN DAN SARAN}

Dari hasil penelitian disimpulkan bahwa terdapat pengaruh service experience dan perceived value terhadap kepuasan pasien. Hal ini menunjukkan bahwa peningkatan kualitas service experience dan perceived value dapat meningkatkan kepuasan pasien pada Instalasi Rawat Inap di RSUD Kota Makassar. 
Selain itu, terdapat pengaruh secara simultan service experience dan perceived value dengan service experience memliki pengaruh paling besar terhadap kepuasan pasien. Ini berarti pasien lebih menekankan pada service experience meskipun peran perceived value juga menentukan kepuasan pasien. Dalam memahami hubungan ini, pihak rumah sakit untuk memberikan focus yang kuat pada pemberian service experience terbaik serta meningkatkan perceived value terhadap pelayanan di rumah sakit sehingga dapat mewujudakn kepuasan pasien sesuai dengan standar yang ditetapkan.

\section{DAFTAR PUSTAKA}

Akbar, S. et al. (2016). A Review : Customer Perceived Value and its Dimension Asian Journal of Social Sciences A Review: Customer Perceived Value and its Dimension.

Ali, H. M. (2007). Predicting the Overall Perceived Value of a Leisure Service: a Survey of Restaurant Patrons in Pretoria Magister Commercii (Marketing Management).

Alrubaiee, L. (2011). The Mediating Effect of Patient Satisfaction in the Patients â $€^{\mathrm{TM}}$ Perceptions of Healthcare Quality Patient Trust Relationship, 3(1), pp. 103-127.

Arab, M. et al. (2014). Developing a Persian inpatient satisfaction questionnaire. Internaional Journal of Health Care Quality Assurance, 27, pp. 4-14.

Berry, L. L., Wall, E. a. and Carbone, L. P. (2006). Service Clues and Customer Assessment of the Service Experience: Lessons from Marketing. Academy of Management Perspectives, 20(2), pp. 43-57.

Chiang, C. and Lee, L. (2013). An Examination of Perceived Value Dimensions of Hotel Visitors : Using Exploratory and Confirmatory Factor Analyses, 8(1), pp. 167-174.

Cronin Jr, J. J., Brady, M. K. and Hult, G. T. M. (2000). Assessing the effects of quality, value, and customer satisfaction on consumer behavioral intentions in service environments, Journal of Retailing, 76(2), pp. 193-218.

Dobrota, M., Nikodijevic, A. and Dobrivojec, M. (2012). Influence of The Customer
Experience On Satisfaction With Mobile Phones', Engineering Management and Competitiveness (JEMC), 2(2), pp. 69-75.

Guo, M. (2012). Service Experience from Customers' Point of View'.

Haeckel, S. H., Carbone, L. P. and Berry, L. L. (2003). How to Lead the Customer Experience', Marketing Management, 12(1), pp. 18-23.

Helkkula, A. (2011). Characterising the Concepr of Service Ezperience. Journal of Service Management, 22(3), pp. 367-389.

Huei, C. T., Mee, L. Y. and Chiek, A. N. (2015) 'A Study of Brand Image, Perceived Service Quality , Patient Satisfaction and Behavioral Intention among the Medical Tourists'.

Khan, I., Jain, R. and Rahman, Z. (2015) 'Customer Service Experience in Hotel Operations: An Empirical Analysis', Procedia - Social and Behavioral Sciences. Elsevier B.V., 189, pp. 266274.

Koné Péfoyo, A. J. and Wodchis, W. P. (2013) 'Organizational performance impacting patient satisfaction in Ontario hospitals: a multilevel analysis.', BMC research notes, 6, p. 509.

Li, J. (2013) 'Factors Affecting Customer Satisfaction and Customer Loyalty towards Belle Footwear Company in Lanzhou City, Gansu Province of the People' s Republic of China', Journal of Business and Management, 14(2), pp. $41-48$.

Maklan, S. and Klaus, P. (2011) 'Customer Experience: Are We Measuring the Right Things?', International Journal of Market Research, 53(6), pp. 1-22. doi: 10.2501/IJMR-53-6-771-792.

Marshall, G. N. and Hays, R. D. (1994) 'The Patient Satisfaction Questionare ShortForm (PSQ-18)', pp. 1-36.

McDougall, G. H. G. and Levesque, T. (2000). Customer satisfaction with services: putting perceived value into the equation', Journal of Services Marketing, 14(5), pp. 392-410.

Milfelner, B. (2009). Measurement of Perceived Quality, Perceived Value, Image, and Satisfaction Interrelations of Hotel Services: Comparison of Tourists from Slovenia and Italy.

Moliner, M. A. (2006). Hospital Perceived 
Value, pp. 328-336.

Moliner, M. A. (2009). Loyalty , perceived value and relationship quality in healthcare services.

Nazri, M., Raji, A. and Zainal, A. (2016). he effect of customer perceived value on customer satisfaction: A case study of Malay upscale restaurants. 3(3), pp. 5868.

Prabhu, S. and Kazi, R. (2016) 'Literature Review of Service Encounter Management , using Emotions Management', 9(45).

Rahmani, Z. et al. (2017) 'The study of the relationship between value creation and customer loyalty with the role of trust moderation and customer satisfaction in Sari hospitals', pp. 4474-4478.

Surydana, L. (2017) 'Service Quality , Customer Value and Patient Satisfaction on Public Hospital in Bandung District, Indonesia', 7(2), pp. 187-192.

Strategy; Systemtic Review, Annal of Internal Medicine.

WHO. (2007). WHO Collaborating cenetrfor patient safety. Joint Comission and Joint Comission International Solutions.
Tseng, M. M., Qinhai, M. and Su, C.-J. (1999) 'Mapping customers' service experience for operations improvement', Business Process Management Journal, 5(1), pp. 50-64.

$\mathrm{Wu}, \mathrm{H} ., \mathrm{Li}, \mathrm{T}$. and Li, M. (2016) 'A Study of Behavioral Intentions , Patient Satisfaction, Perceived Value, Patient Trust and Experiential Quality for Medical Tourists A Study of Behavioral Intentions , Patient Satisfaction', 98.

Yulianti, M. (2017) 'Pengaruh Service Experience terhadap Kepuasan Pelanggan di Instalasi Rawat Inap RSUD A.M Parikesit Kabupaten Kutai Kartanegara', Magister Administrasi Rumah Sakit Prodi Kesmas UNHAS.

Zarei, E. et al. (2015) 'An Empirical Study of the Impact of Service Quality on Patient Satisfaction in Private Hospitals , Iran', 7(1), pp. 1-9. 